\title{
Nesiritide, Heart Failure, and Renal Dysfunction: Irrational Exuberance or Throwing the Baby out with the Bathwater
}

\author{
Editorial to: "Impact of Nesiritide on Renal Function and Mortality in Patients Suffering \\ from Heart Failure" by Dontas et al.
}

\author{
Ronald M. Witteles
}

Published online: 8 April 2009

(C) Springer Science + Business Media, LLC 2009

In this issue of Cardiovascular Drugs and Therapy, Dontas and colleagues have presented a comprehensive review of nesiritide's effects on renal function and mortality in heart failure patients [1]. There is much to be learned from the rise and fall of nesiritide - reflecting as much about the impact of positive and negative publicity on practice behavior as it does about science. Yet, after all the controversy is stripped away, there is little mystery regarding nesiritide's effects; the clinical findings match the expected physiology precisely.

\section{Nesiritide: Physiology}

B-type natriuretic peptide (BNP) acts via the Natriureitc Peptide Receptor-A, which is expressed in high concentration in the vasculature, adrenal glands, and kidneys [2]. Its effects largely counterbalance those of the other dominant cardio-renal neurohormonal axis, the rennin-angiotensinaldosterone system. In the kidneys, BNP's effects come in two forms: direct and indirect.

BNP's direct effects cause an increase in the glomerular filtration rate (GFR). By causing dilation of the afferent renal arterioles and constriction of the efferent renal arterioles, intraglomerular pressure is increased-leading to increased GFR. BNP stimulation also leads to relaxation of renal mesangial cells-increasing the surface area for filtration and further increases in GFR. [2]

R. M. Witteles $(\bowtie)$

Division of Cardiovascular Medicine,

Stanford University School of Medicine,

300 Pasteur Dr., Falk Cardiovascular Research Center \#273,

Stanford, CA 94305-5406, USA

e-mail: witteles@stanford.edu
BNP's indirect effects cause a decrease in GFR. As a potent vasodilator, BNP lowers systemic blood pressure, decreasing renal blood flow and hence decreasing GFR. In addition, BNP inhibits angiotensin II production. Because angiotensin II normally causes constriction of the efferent renal arterioles (increasing GFR), inhibition of angiotensin II leads to decreased GFR.

Therefore, one would expect that the effect of BNP (or nesiritide, recombinant BNP) on GFR depends on the balance between direct and indirect effects. Specifically, one would expect that the direct effects might win out at low doses which do not cause frank hypotension, but that the indirect effects might win out at higher doses in which hypotension occurs. On the other hand, both direct effects (direct inhibition of sodium absorption) and indirect effects (inhibition of angiotensin II, aldosterone, and vasopressin) would be expected to promote natriuresis and diuresis.

Many preclinical and early clinical studies supported these concepts. Small carefully monitored studies in dogs, healthy individuals, and heart failure patients demonstrated enhanced natriuresis, with generally modest but favorable effects on GFR [3-6]. Notably, these studies usually did not employ a bolus.

\section{Pharmacology 101: Bolus vs. No Bolus}

The general purpose of a bolus is to rapidly achieve steadystate levels of a medication, usually for an agent with a long half-life in which it would otherwise take a long period of time to reach steady-state levels. A quick review of nesiritide's pharmacology reveals that the approved dosing scheme for it was not designed to achieve this goal. Specifically, the Food and Drug Administration (FDA)approved starting dose is a $2 \mathrm{mcg} / \mathrm{kg}$ intravenous bolus, 
followed by a constant infusion at $0.01 \mathrm{mcg} / \mathrm{kg} / \mathrm{min}$ [7]. Hence, the bolus is equivalent to the same amount of drug infused over $200 \mathrm{~min}$ - this for a drug with a half-life of less than 20 min [7]. Clearly, the bolus results in a much higher concentration of nesiritide in the bloodstream than is ultimately present at steady state. How and why did this happen?

The answer to this question lies in the design of the pivotal trial which led to nesiritide's FDA approval. VMAC was a randomized trial comparing three interventions in acute heart failure: nesiritide, intravenous nitroglycerin, and placebo [8]. The study population consisted of patients hospitalized with decompensated heart failure who had dyspnea at rest. The primary endpoint of the trial compared nesiritide with placebo for change in symptom scores (primarily designed to assess dyspnea) and wedge pressure three hours after the initiation of therapy. As any physician who treats heart failure knows, the quickest way to improve dyspnea in a patient with elevated filling pressures is to administer a large dose of a vasodilator; by choosing dyspnea symptom scores and wedge pressure as the primary endpoint, it was almost assured before the first patient was enrolled that nesiritide would outperform both the group receiving placebo and the group receiving lowdose nitroglycerin.

Not surprisingly, there are potential downsides to administering a large dose of a vasodilator - most notably the resultant hypotension and hypotension-induced renal dysfunction (the 'indirect' effects of nesiritide). Indeed, contained in the FDA's approval of nesiritide were cautions about possible worsening of renal function and trends toward increased mortality in the nesiritide group-but these warnings originally garnered little attention.

\section{Early use: Irrational exuberance}

Because of the enhanced natriuresis and diuresis clinically observed with nesiritide infusion, as well as anecdotal experiences in which GFR improved with nesiritide infusion (presumably as a consequence of its 'direct' effects), a widespread believe emerged that nesiritide improved renal function in patients with heart failure. This fundamental confusion about the natriruetic/diuretic effects vs. the GFR effects largely persisted, and many subsequently accused nesiritide's manufacturer of encouraging this misconception [9]. Because of this, sales of nesiritide rose dramatically, allowing it to quickly become the most commonly used intravenous heart failure therapy [10].

Enthusiasm became even more robust after results of the FUSION-I trial were reported. This study of 210 heart failure outpatients tested the hypothesis that intermittent outpatient nesiritide infusions (a process which had become very common, and which the company was later widely criticized for promoting [9]) found a lower rate of hospitalizations and all-cause mortality in high-risk patients receiving nesiritide, though there was no significant difference in the overall cohort [11]. Of note, the nesiritide bolus was used in this study (albeit at half-dose in 50\% of the nesiritide group). The decision to include a bolus is difficult to explain on a physiologic level (as, by definition, these were outpatients in whom the 60-90 min it would take to reach steady state drug levels would not be an issue), and presumably was chosen because this dosing scheme is what the FDA had approved on the basis of the VMAC trial. Enthusiasm for nesiritide was so strong that the company which owned it was sold for $\$ 2.4$ billion in 2003 largely on the basis of predicted sales of this single agent [12].

\section{Downfall}

The downfall of nesiritide was as quick as it was precipitous. Shortly after FUSION-I results were released, a manuscript by Wang et al was published representing the first study to test nesiritide's effects on renal function [13]. The very fact that this study of only 15 patients with neutral results was considered newsworthy enough to be published in Circulation highlights the point that in late 2004, the widespread belief (without data to support it) was that nesiritide was beneficial for renal function. These 15 patients who purportedly had decompensated heart failure and volume overload-but who were dosed with diuretics to achieve a neutral fluid balance - showed no change in GFR with a nesiritide infusion (including a bolus) vs. placebo [13].

However, the real downfall emerged with the publication and widespread publicity of two articles published in highimpact journals in early 2005. These represented two metaanalyses of nesiritide trials, and they concluded that nesiritide use was associated with worsened renal function and possibly increased mortality [14, 15]. Though there were criticisms of these analyses (including the fact that the 'control' therapy in the trials varied from inotropes to vasodilators to 'non-inotrope based controls'), and other analyses disputed the findings $[16,17]$, their publication led almost immediately to a large drop in nesiritide's use and calls for the FDA to reconsider its approval [9, 10].

\section{Throwing the baby out with the bathwater}

The real story, not surprisingly, lay not with nesiritide being inherently a 'good' or 'bad' drug, but in how the drug was used and in what patient population it was tested. Our 
group performed what remains the only randomized controlled trial in the volume overloaded acute decompensated heart failure population designed to specifically evaluate renal dysfunction. The study found that when use of the bolus was left to the discretion of the treating physician (who held it one-third of the time), nesiritide infusion had no overall impact on renal function [18]. In this study, the direct effects presumably balanced the indirect effects as a whole.

The FUSION-II trial studied a similar patient population as FUSION-I and again included a bolus dose of $2 \mathrm{mcg} / \mathrm{kg}$. While the study showed no benefit for nesiritide's use (not surprisingly to many-as there would be little reason to believe that intermittent infusion of a vasodilator would affect long-term heart-failure outcomes), there once again was no impact either way on renal function [19].

Much can also be learned from the NAPA study, published in 2007. In this trial, 279 patients with systolic dysfunction undergoing coronary artery bypass grafting were randomized to receive nesiritide or placebo for 24 $96 \mathrm{~h}$ [20]. Importantly, this represents the only major trial which did not give a bolus to any patient, and all patients had close hemodynamic monitoring-likely further lowering the chance of hypotension associated with nesiritide administration. In this setting, the 'direct' effects likely took precedence over the 'indirect' effects, and - presumably for this reason - this is the only trial to conclusively demonstrate improved renal function (and survival) in the nesiritide group.

\section{Where are we today?}

Nesiritide remains an agent whose properties cannot be recapitulated with any other currently available drug. Specifically, nesiritide is a balanced vasodilator-lowering preload more than nitroprusside, and afterload more than nitroglycerin - and possesses unique natriuretic/diuretic properties. Its 'direct' renal effects likely lead to the profound improvement in renal function in individual patients anecdotally reported by many clinicians, but this effect is lost when it is overcome by decreased renal perfusion caused by its indirect effects.

More than anything, the story of nesiritide teaches valuable lessons. In order to achieve FDA approval, an indication was sought in which administering an overly large bolus was beneficial to meeting the definitive trial's endpoint - albeit at the expense of other outcomes, including renal function. While this strategy resulted in approval of the drug and its widespread early adoption in heart failure treatment algorithms, it ultimately proved to be the drug's downfall - as the renal dysfunction associated with the bolus came to light. A sophisticated understanding of the direct and indirect effects of the drug was lost in the noise, and a drug which had once been inappropriately touted as 'renal-protective' took on the equally inappropriate image of being intrinsically 'renal-toxic.'

As the NAPA trial demonstrated, a unique role for nesiritide exists to this day. Clinicians who recognize this value, and who avoid administering the misconceived bolus, can still achieve benefit for their patients-allowing the bathwater to be thrown out without the baby.

\section{References}

1. Dontas I, Xanthos T, Dontas I, Lelovas P, Papadimitriou L. Impact of nesiritide on renal function and mortality in patients suffering from heart failure. Cardiovasc Drugs Ther. 2009;23: This issue.

2. Davidson NC, Struthers AD. Brain natriuretic peptide. J Hypertens 1994;12:329-36.

3. Holmes SJ, Espiner EA, Richards AM, Yandle TG, Frampton C. Renal, endocrine, and hemodynamic effects of human brain natriuretic peptide in normal man. J Clin Endocrinol Metab 1993;76:91-6.

4. Marcus LS, Hart D, Packer M, et al. Hemodynamic and renal excretory effects of human brain natriuretic peptide infusion in patients with congestive heart failure. A double-blind, placebocontrolled, randomized crossover trial. Circulation 1996;94:3184-9.

5. Mills RM, LeJemtel TH, Horton DP, et al. Sustained hemodynamic effects of an infusion of nesiritide (human b-type natriuretic peptide) in heart failure: a randomized, double-blind, placebocontrolled clinical trial. Natrecor Study Group. J Am Coll Cardiol 1999;34:155-62.

6. Scriven TA, Burnett JC Jr. Effects of synthetic atrial natriuretic peptide on renal function and renin release in acute experimental heart failure. Circulation 1985;72:892-7.

7. Natrecor (nesiritide) for Injection: Package Insert. (Accessed February 8, 2009, at http://www.fda.gov/cder/foi/label/2006/ 020920s012lbl.pdf.)

8. Publication Committee for the VMAC Investigators (Vasodilatation in the Management of Acute CHF). Intravenous nesiritide vs nitroglycerin for treatment of decompensated congestive heart failure: a randomized controlled trial. JAMA 2002;287:1531-40.

9. Topol EJ. Nesiritide— not verified. N Engl J Med 2005;353:113-6.

10. Hauptman PJ, Schnitzler MA, Swindle J, Burroughs TE. Use of nesiritide before and after publications suggesting drug-related risks in patients with acute decompensated heart failure. JAMA 2006;296:1877-84.

11. Yancy CW, Saltzberg MT, Berkowitz RL, et al. Safety and feasibility of using serial infusions of nesiritide for heart failure in an outpatient setting (from the FUSION I trial). Am J Cardiol 2004;94:595-601.

12. Gellene D. For Scios CEO, sale is close to the heart. Los Angeles Times February 11, 2003:C-1.

13. Wang DJ, Dowling TC, Meadows D, et al. Nesiritide does not improve renal function in patients with chronic heart failure and worsening serum creatinine. Circulation 2004;110:1620-5.

14. Sackner-Bernstein JD, Kowalski M, Fox M, Aaronson K. Shortterm risk of death after treatment with nesiritide for decompensated heart failure: a pooled analysis of randomized controlled trials. JAMA 2005;293:1900-5.

15. Sackner-Bernstein JD, Skopicki HA, Aaronson KD. Risk of worsening renal function with nesiritide in patients with acutely decompensated heart failure. Circulation 2005;111:1487-91. 
16. Abraham WT, Adams KF, Fonarow GC, et al. In-hospital mortality in patients with acute decompensated heart failure requiring intravenous vasoactive medications: an analysis from the Acute Decompensated Heart Failure National Registry (ADHERE). J Am Coll Cardiol 2005;46:57-64

17. Arora RR, Venkatesh PK, Molnar J. Short and long-term mortality with nesiritide. Am Heart J 2006;152:1084-90.

18. Witteles RM, Kao D, Christopherson D, et al. Impact of nesiritide on renal function in patients with acute decompensated heart failure and pre-existing renal dysfunction a randomized, double- blind, placebo-controlled clinical trial. J Am Coll Cardiol 2007;50:1835-40.

19. Yancy CW, Krum H, Massie BM, et al. Safety and efficacy of outpatient nesiritide in patients with advanced heart failure: Results of the second follow-up serial infusions of nesiritide (FUSION II) trial. Circ Heart Fail 2008;1:9-16.

20. Mentzer RM Jr, Oz MC, Sladen RN, et al. Effects of perioperative nesiritide in patients with left ventricular dysfunction undergoing cardiac surgery:the NAPA Trial. J Am Coll Cardiol. 2007;49:716-26. 